\title{
Especial
}

\section{RESISTÊNCIA E RESTAURAÇÃO DE IDENTIDADES NO TEATRO DA MICRORREGIÃO DE PELOTAS}

\section{RESISTANCE AND IDENTITY RESTORATION IN THE THEATER OF THE PELOTAS MICROREGION}

\section{RESISTENCIAS Y RESTAURACIÓN DE IDENTIDADES EN EL TEATRO DE LA MICRORREGIÓN DE PELOTAS}

\section{Adriano Moraes de Oliveira}

\section{Adriano Moraes de Oliveira}

Professor adjunto na Universidade Federal de Pelotas. Bacharel em artes cênicas

(interpretação) pela UEL, mestre em teatro pela UDESC e doutor em educação pela UFPEL

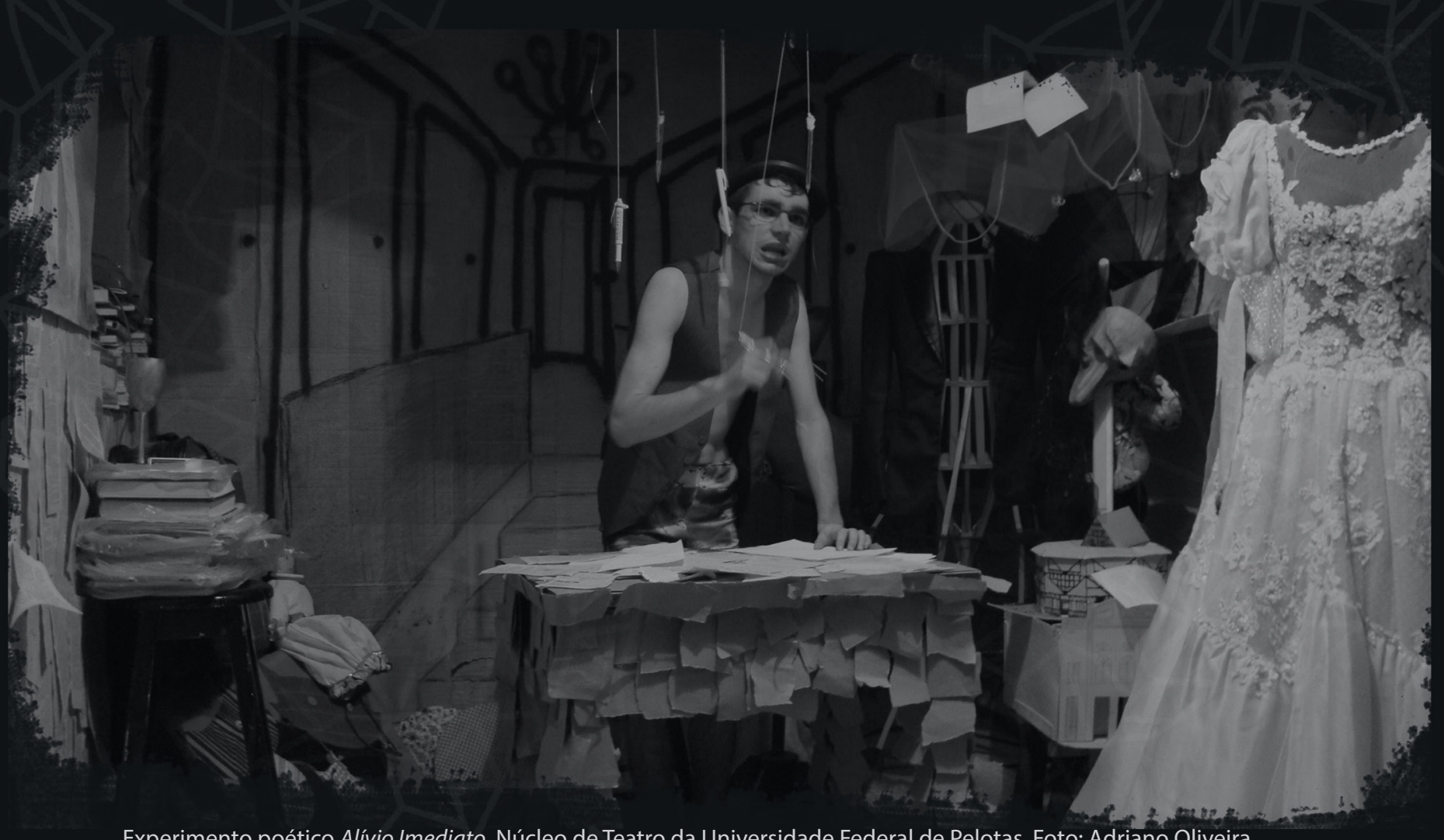




\section{Resumo}

O presente texto é resultado de uma pesquisa realizada entre 2012 e 2014 com o objetivo de mapear os grupos teatrais em atividade na microrregião de Pelotas, com o interesse de ampliar o conhecimento sobre as práticas teatrais desse espaço geográfico. O mapeamento aponta para uma prática teatral em que as motivações são muito próximas daquelas dos grandes centros econômicos: experimentação de linguagem, investigação de poética, preservação da memória e, obviamente, teatro como empreendimento comercial e de entretenimento. São apresentadas, também, as principais características do teatro na microrregião de Pelotas, de modo a indicar as ações de resistência a novos modelos, mas também a valorização de modelos de atuação por meio da reiterada restauração identitária.

Palavras-chave: Teatro de grupo, Pesquisa teatral, Teatro gaúcho.

\section{Abstract}

This text is the result of the survey conducted between 2012 and 2014, whose aim was to map the theater groups active in the Pelotas microregion, Southern Brazil, with the interest of increasing the knowledge of theatrical practices of this geographical space. The mapping points to a theatrical practice in which the motivations are very close to those of the major economic centers, namely: language experimentation, research of poetics, memory preservation, and, obviously, theater as a commercial and entertainment enterprise. This text also presents the main theater features in the Pelotas microregion to indicate the actions of resistance to new models, but also the appreciation of acting models through reinforced identity restoration.

Keywords: Group theatre, Theatrical research, Gaucho theater.

\section{Resumen}

Este artículo es el resultado de una investigación realizada entre 2012 y 2014, cuyo objetivo fue el de sondear a los grupos teatrales en actividad en la microrregión de Pelotas, con el propósito de ampliar el conocimiento sobre las prácticas teatrales de ese espacio geográfico. Este sondeo se dirige a una práctica teatral en que las motivaciones son muy cercanas a aquellas de los grandes centros económicos, o sea: la experimentación del lenguaje, la investigación sobre la poética, la preservación de la memoria y, evidentemente, el teatro como emprendimiento comercial y de entretenimiento. En este artículo también se presentan las principales características del teatro en la microrregión de Pelotas con la intención de señalar las acciones de resistencia a los nuevos modelos y al mismo tiempo la valorización de modelos de actuación a través de la reiterada restauración identitaria.

Palabras clave: Teatro de grupo, Investigación teatral, Teatro gaúcho. 


\section{Introdução}

O ponto de partida para a presente reflexão é uma pesquisa realizada entre 2012 e 2014 que objetivou mapear os grupos de teatro em atividade na região sul do Rio Grande do Sul. Para tanto, foram consultados exemplares dos dois jornais com maior abrangência da referida região, realizadas visitas in loco em mais de 20 municípios e gravadas entrevistas com artistas, produtores e gestores.

O conjunto dos dados está em fase de processamento e análise, e as reflexões realizadas durante a primeira fase de pesquisa foram publicadas no livro Sobre o teatro na região de Pelotas: primeira abordagem de pesquisa (2014).

A abordagem realizada em relação ao teatro na região de Pelotas foi, inicialmente, uma ação política pessoalizada com o claro interesse de escancarar a quase total falta de atenção para os modos de produção teatrais presente na cidade. Essa falta de atenção é facilmente detectável. Basta, para tanto, a informação de que dos sete teatros em funcionamento até a década de 1960 apenas um está - no momento - em pleno funcionamento. Dentre os teatros fechados há mais de cinco anos está o Theatro Sete de Abril, prédio inaugurado em 1834 e patrimônio histórico nacional.

A ideia de realizar uma pesquisa que pudesse mapear as condições dos grupos e trabalhadores do teatro na região de Pelotas, embora iniciada com uma motivação política e pessoal, tomou outros rumos. Com isso, o corolário da investigação passou a considerar os modos como grupos e artistas de teatro dessa microrregião resistiam às intempéries político-culturais e como o processo de restauração de modos de trabalho do passado se faz presente na maior parte dos processos criativos dos artistas e grupos locais.

Acrescenta-se a essa advertência que a coordenação da pesquisa esteve a cargo de um professor-artista que iniciou sua carreira num contexto de teatro de grupo de outro interior do país. Ou seja, a ação da pesquisa, embora amparada em metodologias específicas, foi permeada pela experiência do coordenador da investigação sobre o fazer teatral distante dos eixos com maior concentração econômica.

O que se apresenta, neste momento, é um conjunto de cenários dos modos de ser dos grupos e artistas de teatro mapeados na microrregião que 
ladeia a fronteira sul do Brasil. Fala-se de teatro microrregional em relação à abrangência e ao impacto do trabalho. Nesse sentido, um teatro de um grupo da região é microrregional quando sua abrangência é apenas no limite das cidades que compõem a microrregião de Pelotas.

\section{Ponto de partida e referências da pesquisa}

O ponto de partida para a pesquisa foi o contraditório discurso presente nos meios públicos de divulgação sobre a forte tradição teatral da cidade e região de Pelotas. Por conta de que os discursos podiam ser rapidamente refutados em função da precariedade evidente da maior parte dos grupos de teatro da região, optou-se por trabalhar com referenciais teóricos que garantissem o máximo de isenção em relação ao que o senso comum entende por tradição teatral. Em primeiro lugar, buscou-se nas teorias do imaginário a compreensão para a estrutura mítica e como esta se consolida e, até, se cristaliza na apreensão dos fatos cotidianos. Por outro lado, foram assumidas a ideia de hipermodernismo de Lipovetski e, mais precisamente, a noção de "capitalismo artista" para compreender as intimações do fazer teatral na atualidade.

Às questões do imaginário foram adotados os estudos de Maffesoli (2004, 2005 e 2010), cujo anteparo teórico possibilitou a compreensão de que as estruturas arcaicas do imaginário se fazem presentes na atualidade com roupagens novas. Ou seja, amparado nos estudos de Maffesoli, ficava impossível a refutação da noção de tradição teatral presente no discurso, mas não na maior parte da prática.

Para a teoria do imaginário, a própria verbalização garante a presença. Se havia o mito da tradição teatral, mesmo que apenas de modo discursivo, era importante verificar as configurações dessa tradição. Com isso, a própria palavra "teatro" foi problematizada e passada a ser entendida em suas diversas significações: arte efêmera que tem como principal característica a presença intencional de uma ação proposta por um ou mais artistas diante de espectadores, espaço em que se executa o encontro social entre espectadores e artistas da cena, ação social que se utiliza de forma figurativa para a comunicação, dentre outras. Essa arbitrariedade de se assumir os discursos do imaginário para o entendimento do fazer teatral da microrregião de Pelotas 
proporcionou que entendêssemos essa tessitura social sem refutar qualquer possibilidade. Para Maffesoli (2010),

[...] é justamente na medida em que não se decreta o que "deve ser" uma sociedade (assim como tal ou qual de seus membros) que o sociólogo precisa saber apreciar, em suas proporções e sem a priori todas as histórias, todas as justificações, todas as legitimações que, de maneira polifônica, constituem o discurso do social. (p. 92)

Isso demandou de toda a equipe da pesquisa uma postura de compreensão em relação tanto aos discursos da suposta tradição teatral no presente como no trato com os artistas e grupos que, mesmo em situação de absoluta precariedade, defendiam essa tradição pouco evidente em seus cotidianos. Tendeu-se, em diversos momentos da pesquisa, a considerar apenas o discurso, mas como as cidades que compõem a microrregião de Pelotas possuem vestígios importantes de forte manifestação teatral - prédios, anedotas, dramaturgias - essa tendência foi freada. Em vez de fecharmo-nos à tendência de refutar uma tradição não evidente no fazer cotidiano dos grupos, procedemos a uma abertura que permitisse aceitar todas as manifestações teatrais como legítimas herdeiras da tradição passada.

Essa postura metodológica compreensiva promoveu uma ampliação do escopo da pesquisa. Não era possível considerar apenas os aspectos convencionais das manifestações teatrais, mas também incluí-las ao leque de manifestações que possuía algum grau de teatralidade, inclusive aquelas promovidas pela esfera extra-arte, a do capitalismo artista.

Para Lipovetski e Serroy, o capitalismo artista é a fase do capitalismo que assume o estético como elemento mais importante para agregar valor a um serviço ou objeto. O processo de estetização do mundo - sua espetacularização, sua teatralização etc. - é a marca mais emblemática desse capitalismo que abarca todo e qualquer discurso e prática social transformando-o em bem de consumo. Com o capitalismo artista, o teatro como arte perde valor em si e passa a ter maior valor na ação social. Não é o teatro ou uma peça teatral em si que causa maior interesse, mas o valor estético de consumir teatro ou se fazer presente em um espetáculo que proporciona valor. Para Lipovetski e Serroy (2015), 
[...] é preciso se convencer de que o capitalismo artista não é apenas produtor de bens e de serviços mercantis, ele é ao mesmo tempo "o lugar principal da produção simbólica", o criador de um imaginário social, de uma ideologia, de mitologias significantes. A sociedade de consumo "é o próprio mito dela mesma" [Baudrillard], um mito sem grandeza, sem exterioridade sem transcendência, mas que constitui "um discurso pleno, autoprofético, que a sociedade faz sobre si mesma, um sistema de interpretação global", uma constelação inédita de valores capaz de fazer as massas sonharem (p. 126).

A entrada dessa análise da conjuntura macroeconômica global estimulou-nos a pensar as manifestações teatrais de Pelotas e cidades da região de acordo com a demanda simbólica local. Com isso, foi possível constituir cenários das imagens que se fazem presentes na produção teatral de Pelotas e região. De forma geral, as manifestações teatrais da microrregião de Pelotas podem ser classificadas em termos de vínculos matriciais, sendo os seguintes cenários: (1) um teatro que busca restaurar modos de fazer do passado; (2) um teatro que é feito a partir de diálogo com matrizes contemporâneas da arte, principalmente a erudita ou legitimada por autoridade especializada; (3) um teatro que atende às demandas da moda e do entretenimento; (4) um teatro vinculado ao nativismo gaúcho e a tradições populares; e (5) um teatro experimental e alternativo - o teatro universitário.

\section{Cenário 1: a presença do passado}

O senso comum do fazer teatral na microrregião de Pelotas é pautado por um passado em que era comum e quase cotidiano espetáculos nacionais e internacionais se apresentarem na cidade. Esse passado promoveu a criação de um imaginário bastante consolidado por meio de uma forte movimentação cultural e que ainda se faz presente nos discursos de artistas, gestores e espectadores.

Contribuem para a manutenção dessa mitologia a forte influência da cultura europeia (principalmente na arquitetura da cidade) e o número significativo de espectadores de música, de dança e de teatro que ainda frequentam os eventos sazonais. Alguns dos equipamentos construídos num período de efervescência cultural já não existem mais, mas a memória dos 
mais de dez teatros de médio porte (mais de 500 lugares cada um) da microrregião de Pelotas é bastante concreta. As histórias de um passado de intenso movimento cultural povoam as conversas nos cafés e doçarias da cidade.

Para ilustrar esse contexto de efervescência, apresento alguns dados que levantamos em jornais da cidade e que estão em fase de análise: entre a década de 1930 e 1950 foram apresentados na cidade de Pelotas 727 espetáculos de teatro. Entre as companhias teatrais que estiveram na cidade estão: Cia. De Revistas e Sainetes Sper, Cia. Nacional de Revistas Pinto Filho, Cia. Dulcina-Durães, Cia. Zaira Médici, Cia. Brasileira de Revistas, Cia. Palmeirim Cecy Medina, Cia. Teatro de Caboclo, Cia. Nacional de Comédias Darci Casarré, Cia. de Fantoches Italo-Brasileira, Cia. Dulcina Odilon, Cia. Iracema de Alencar, Cia. Cazarré-Elza-Delorges, Cia. Alvaro Moreyra, Cia. Lison Gaster, Cia. de comédias Ribeiro Cancela, Cia. Alda Garrido, Cia. de Comédias Mesquitinha Alma Florinda, Cia. de Comédias Suzana Negri, Cia. Genésio Arruda, Cia. Portuguesa de revistas Beatriz Costa, Cia. de Comédias Jaime Costa, Cia. Brasileira de Comédias, Cia. Lison Gaster, Cia. Renato Viana, Cia. Procópio Ferreira, Cia. Nino Nello, além de diversas companhias de opereta, circo-teatro e dança.

O motivo dessas visitas de companhias cariocas e paulistanas, segundo Faria (2001), pode ter sido a constante presença de grandes companhias estrangeiras no eixo Rio-São Paulo. Segundo esse autor e também Prado (1999), as excursões de companhias brasileiras pelo país eram motivadas pela concorrência de artistas e companhias estrangeiras. Independentemente da motivação e dos problemas que causaram essas viagens às companhias, é interessante perceber que uma cidade de médio porte, para a época, era visitada por companhias de teatro, na maior parte dos casos com espetáculos cômicos e revistas. A influência dessas presenças nas rotinas dos artistas e grupos locais não pode ser mensurada, mas também não negada.

Esse primeiro cenário nos permite afirmar que a história do teatro na cidade de Pelotas até a década de 1960 é muito semelhante à história do teatro brasileiro até esse mesmo período. A cidade era preparada para receber grupos de teatro de qualquer localidade e, pelo que consta nos jornais da época, muitas temporadas tiveram de ser prolongadas em função do número de espectadores. Há, inclusive, nesse primeiro cenário, a presença de um 
importante grupo de teatro - o Teatro Escola de Pelotas (TEP), que desde 1914 se mantém em atividade na cidade. Provavelmente é um dos grupos mais antigos do Brasil com atividades continuadas, embora com pequenos interstícios circunstanciais.

Esse cenário inicial persiste, atualmente, na figura do TEP, mas também no modo como a criação teatral é, ainda, promovida de modo tradicional, em que o diretor é o artista-criador par excellence, o texto dramático é entendido como princípio criativo fundamental e o espaço teatral com frontalidade é o principal limite para a imaginação.

Desse cenário iniciado no século XIX e ainda muito presente nos modos de ser do teatro na microrregião de Pelotas, pode-se entender que o que se busca é também uma restauração de uma realidade em que a cultura, particularmente o teatro, recebia mais investimentos. Os grandes teatros - o Sete de Abril e o Guarany - seguem como lugares de referência para boa parte dos grupos oriundos da prática do TEP. É um cenário que resiste às intempéries culturais e econômicas e que tem cada vez mais dificuldades em seus processos de restauração.

\section{Cenário 2: a referência do teatro de arte}

A partir de 1962 e com a diminuição da circulação de espetáculos pelo país (129 apresentações teatrais no período de 1961 a 1970 contra 232 apresentações no período de 1951 a 1960), em função, principalmente, do período de controle ideológico pela ditadura militar, surgiram organizações muito importantes para o teatro local: a STEP (Sociedade de Teatro de Pelotas) e a Asateatro (Associação do Atores de Pelotas).

Essas associações foram responsáveis por promover um debate de modo organizado com instituições, grupos e pensadores do teatro. O principal meio encontrado para estimular o teatro foi a promoção de festivais em que artistas locais, regionais, nacionais e internacionais se encontravam. Os festivais se confirmaram como importantes momentos de troca de saberes e estímulo à formação de artistas e plateia.

No período dos festivais foram realizadas em Pelotas, principalmente, oficinas e residências artísticas importantes com grupos como LUME (Cam- 
pinas), Tribo de Atuadores Ói Nóis Aqui Traveiz (Porto Alegre), PROTEU (Londrina, já extinto), entre outros. A presença desses grupos estimulou a formação de grupos locais com interesse para criar obras de teatro para além dos palcos tradicionais.

Dois espetáculos são emblemáticos no que se refere ao impacto que os festivais tiveram na produção local, principalmente em Pelotas. O primeiro deles é Estudo do feminino $n^{\circ} 1$ - o belo indiferente (2002), do Grupo Teatro de Areia, com os atores Igor Simões e Vagner Vargas, e o Deu Libório na cabeça (2004), de André Macedo, com o ator Acevesmoreno. Esses trabalhos evidenciam uma preocupação para além do entretenimento e têm uma preocupação com a própria arte: o primeiro, por apresentar uma dramaturgia não dramática em um dos teatros mais tradicionais da cidade; o segundo, por ocupar um espaço alternativo e uma relação da cena com espectadores de modo inovador.

Alguns grupos continuam a fazer experiências cênicas em espaços alternativos e utilizando com clareza referências contemporâneas da arte teatral. A fase inaugurada com os festivais dos anos 1970 e 1990 é sempre lembrada pela renovação que o contato com outros artistas e grupos promovia na produção da cidade e da região.

\section{Cenário 3: o teatro de consumo e de entretenimento}

O teatro de grupo voltado para consumo e entretenimento tem sido uma tônica na região desde o final dos anos 1990. Um dos exemplos mais emblemáticos é a empresa circense Grupo Tholl que, mimetizando o trabalho do Cirque Du Soleil, explora elementos do circo, da ginástica artística, da dança e do teatro. Sediado em Pelotas, o Tholl tem levado seu produto para muitas cidades do estado e do Brasil, além, evidentemente, de integrar os mais diversos eventos de promoção de empresas e produtos.

Do ponto de vista da abrangência, o Tholl não integra apenas o teatro microrregional, embora sua presença seja marcante na região de Pelotas. $O$ apelo midiático do grupo é tamanho, que a palavra "Tholl" se transformou em símbolo de sucesso da cidade. O slogan do grupo - "imagem e sonho" - cria um pano de fundo perfeito para o efeito que esperam produzir: impacto visual, evasão da realidade, entretenimento fluído. 
A influência do Tholl na região é significativa no que se refere ao imaginário amparado num discurso de sucesso e empreendedorismo. Diversos artistas adotam maquiagem, indumentárias e, inclusive, algumas técnicas para, desse modo, aproximarem-se do sucesso do empreendimento Tholl - que, aliás, foi iniciado no âmbito de outro grupo, o Teatro Escola de Pelotas (legítimo representante da tradição). Segundo Santos (2012),

É ainda nos anos 90 que surge no TEP a Oficina Permanente de Técnicas Circenses (OPTC). Sob o comando de João Bachilli, ator de destaque do TEP, o grupo logo depois ganhou autonomia e se tornou um hit nacional nos palcos com o espetáculo Tholl, imagem e sonho. (p. 136)

Evidentemente esse cenário do teatro de consumo e entretenimento se utiliza da mídia e dos discursos da moda para se manter no mercado. Com isso, seu trabalho é muito mais presente nos eventos comerciais da região (festas, exposições de negócios etc.) do que nos palcos. O grupo representa o sucesso do empreendedorismo, e sua principal função é animar socialmente os consumidores. Não é a toa que frequentam a mídia nacional (principalmente os programas de auditório) e possuem seguidores nos mesmos moldes dos grandes astros e estrelas do show business.

\section{Cenário 4: o teatro popular e o nativismo regionalista}

Duas expressões significativas do popular no teatro da microrregião de Pelotas podem ser localizadas em duas tradições: uma nativista e que tem como princípio a manutenção da memória do gaúcho (principalmente a do estancieiro), e outra no circo-teatro, gênero já clássico na região que discute as questões cotidianas. A primeira pode ser vista em Centros de Tradição Gaúcha (CTG) ou Departamentos de Tradição Gaúcha (DTG, que se situam na maioria das escolas da rede de educação básica); a segunda é representada por uma tradicional companhia de circo-teatro liderado pelo palhaço Bebé, o Tchêatro do Bebé. Incluo as duas num mesmo tópico por conta de que os espectadores do circo-teatro e os participantes dos centros tradicionalistas são, geralmente, classe média.

OTchêatro do Bebé é uma companhia com mais de 70 anos de atividade, que segue o modelo de trabalho em família. Seu repertório é composto de dra- 
mas e comédias em que o palhaço Bebé é o personagem central. A companhia atua em toda a região sul do estado, tendo como sede a cidade de Pelotas.

O teatro realizado nos CTG e DTG segue as normativas do Movimento Tradicionalista Gaúcho. Um dos ícones da região é o grupo de Artes EnCenAção, de Piratini, que tem como repertório toda a saga da revolução Farroupilha. O grupo, com sede na cidade que foi a primeira capital da República Riograndense (primeira metade do século XIX), busca manter viva a memória do heroísmo gaúcho, mas também o cotidiano do gaúcho da pampa. Tem um apelo emocional emblemático para os gaúchos em função de servir como elemento de restauração de suas memórias ancestrais. Evidentemente, em função da história narrada nos CTG privilegiar personagens brancos e donos de fazenda e desconsiderar que a região teve um dos maiores contingentes de escravos negros do Brasil, este teatro é alvo de críticas.

\section{Cenário 5: o ambiente acadêmico e o teatro universitário}

Desde a década de 1970, as universidades têm contribuído de modo significativo para o desenvolvimento da arte teatral nas cidades da região. Isso acontece por meio de oficinas e apresentações de espetáculos de núcleos de teatro das três principais universidades da região. Têm trabalho institucional desde a década 1970 as universidades federais de Pelotas e de Rio Grande e, também, a partir da década de 1980, a Universidade Católica de Pelotas e o Instituto Federal Sul Riograndense. Juntas, promovem periodicamente uma série de ações que estimulam não apenas a prática, mas o pensamento sobre o teatro. As universidades mantêm grupos universitários em que é possível a estudantes e comunidade em geral participar de oficinas e espetáculos. O interessante é que o gênero universitário se mantém vivo com dramaturgias de protesto, experimentações de linguagem e reiteração do papel social do teatro.

Em 2008 foi implantado o curso de licenciatura em teatro na Universidade Federal de Pelotas. Com isso e o ingresso anual de cerca de 50 estudantes de teatro, a movimentação teatral ganhou força. São inúmeras as ações nas comunidades, escolas e outros espaços de projetos do curso. Algumas são focadas na pedagogia - estimulando práticas em salas de aula, jogos de 
aprendizagem, dinâmicas, as mais diversas e em consonância com as principais metodologias discutidas e experimentadas no Brasil. Outras são voltadas para a experimentação cênica, apresentando propostas de ocupação de espaços públicos, novas dramaturgias e poéticas teatrais específicas.

Como cenário teatral em uma microrregião, as instituições de educação superior têm importante responsabilidade na formação de artistas e público pelo simples fato de manterem vivas as questões de pesquisa que movimentaram artistas ao longo dos séculos.

\section{O teatro microrregional}

Pensar o teatro no interior do Brasil a partir da perspectiva microrregional é o modo encontrado para iniciar uma narrativa das manifestações teatrais desse interior brasileiro. Em período de acentuada facilidade de intercâmbio comunicacional e, consequentemente, cultural, o teatro produzido nas diversas microrregiões do país guardam peculiaridades e tendem, ao mesmo tempo, ao global. $\mathrm{O}$ acesso a modelos, estudos, imagens e peças é facilitado, e isso interfere de maneira significativo no modo como os grupos e artistas se organizam. Obviamente, o fluxo torrencial de informações gera, também, enormes problemas de leitura em função da desconsideração dos contextos de produção.

Os estímulos econômicos de governos e instituições locais a grupos e espaços para o teatro contribuem para a profusão de modos de se fazer teatro. As instituições, normalmente, exigem a contrapartida de artistas, espaços e grupos em função da política nacional vigente e de acordo com o que o mercado de valores estéticos privilegia (pautado no capitalismo artista global). Com isso, o microrregional sofre de modo semelhante ao teatro com maior abrangência.

\section{Referências bibliográficas}

CAFEZEIRO, E. História do teatro brasileiro: um percurso de Anchieta a Nelson Rodrigues. Rio de Janeiro: Funarte/Editora da UERJ, 1996.

FARIA, J. R. Ideias teatrais: o século XIX no Brasil. São Paulo: Perspectiva, 2001. LIPOVETSKI, G. \& SERROY, J. A estetização do mundo: viver na era do capitalismo artista. São Paulo: Companhia das Letras, 2015. 
MAFFESOLI, M. A parte do diabo: resumo da subversão pós-moderna. Rio de Janeiro: Record, 2004.

A sombra de Dioniso. São Paulo: Zouk, 2005.

O conhecimento comum: introdução à sociologia compreensiva. Porto Alegre: Sulina, 2010.

OLIVEIRA, A. M. As intimações do imaginário a forma-ação do ator-professor: cartas sobre a reeducação do sensível. 2011. Tese (doutorado em educação), Universidade Federal de Pelotas, Pelotas.

OLIVEIRA, A. M. \& PINTANEL, E. O. (orgs.). Sobre o teatro na região de Pelotas: primeira abordagem de pesquisa. Pelotas: GEPPAC, 2014.

PRADO, D. A. História concisa do teatro brasileiro. São Paulo: Edusp, 1999.

SANTOS, K. Sete de Abril: o teatro do imperador. PORTO ALEGRE: LIBRETOS, 2012.

Recebido em 16/08/2015

Aprovado em 14/09/2015

Publicado em 21/12/2015 